\title{
$\mathbf{J}|\mathbf{A}| \mathbf{C} \mid \mathbf{S}$ \\ $\overline{\text { COMMUNICATIONS }}$
}

Published on Web 09/24/2002

\section{Development of a Donor-Acceptor Concept for Enzymatic Cross-Coupling Reactions of Aldehydes: The First Asymmetric Cross-Benzoin Condensation}

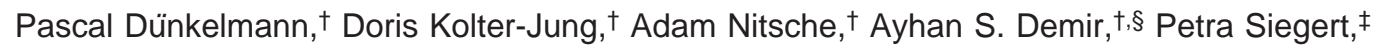 \\ Bettina Lingen, $¥$ Martin Baumann, $¥$ Martina Pohl,,,$\S$ and Michael Müller ${ }^{*}, \uparrow$ \\ Institute of Biotechnology 2, Forschungszentrum Jülich, 52425 Jülich, Germany, and \\ Institute of Enzyme Technology, Heinrich-Heine Universität, Düsseldorf, Germany
}

Received June 3, 2002

In earlier publications, we showed that enantiopure benzoins can be efficiently obtained by use of the thiamin diphosphate (ThDP)dependent enzymes benzaldehyde lyase $(\mathrm{BAL})^{1}$ or benzoylformate decarboxylase (BFD). ${ }^{2}$ In the present contribution we present successful and unprecedented results leading to a donor-acceptor concept for the asymmetric synthesis of mixed benzoins, that is, benzoins with nonidentical aromatic moieties, using an enzymecatalyzed benzoin condensation. An asymmetric variant of this cross-coupling has not yet been described in the literature. ${ }^{3}$

The synthesis of mixed benzoins is of interest in many respects as they are versatile building blocks in organic and pharmaceutical chemistry. ${ }^{4}$ In addition to other synthetic routes the racemic compounds can be synthesized selectively by means of a cyanidecatalyzed cross-benzoin condensation. ${ }^{5}$ This selectivity prompted various scientists to subdivide the aromatic aldehydes into donors, adding the cyanide ion, and acceptors. ${ }^{6}$

Although we do not agree completely with the authors' statements ${ }^{6 \mathrm{c}}$ we were inspired by this idea of selective donors and acceptors so that in an initial experiment 2-chlorobenzaldehyde (2a), 2-methylbenzaldehyde (2b), 2-methoxybenzaldehyde (2c), and subsequently the ortho-substituted benzaldehyde derivatives $\mathbf{2 d}-\mathbf{f}$ were reacted with benzaldehyde in the presence of different ThDP-dependent enzymes. The three substrates $\mathbf{2} \mathbf{a}-\mathbf{c}$ were chosen because of their inability to form symmetrical benzoins through the wild-type BFDcatalyzed reaction, ${ }^{2 \mathrm{a}}$ assuming that they still might serve as acceptor substrates although they are not accepted as donors by this enzyme. Here, the enzymes BFD H281A 7 and BAL were identified as potent catalysts for asymmetric cross-carboligation (Table 1). The absolute configuration of compound $\mathbf{3 a}$ was determined to be $R$, as expected (ee $>99 \%) .{ }^{8}$ This compound has also been synthesized on a preparative scale using BFD H281A as well, with pleasing results concerning conversion and selectivity. Remarkably, the 2,2'disubstituted benzoins $\mathbf{5} \mathbf{a}-\mathbf{c}$ or the mixed benzoins substituted in 2-position $\mathbf{6 a}-\mathbf{c}$ were not generated in the BFD H281A-catalyzed reactions while $\mathbf{5 d} \mathbf{d}, \mathbf{f}$ and $\mathbf{6} \mathbf{d}, \mathbf{f}$ were not formed in the BAL-catalyzed reactions, showing that $\mathbf{2 a}-\mathbf{d}, \mathbf{f}$ react selectively as acceptors in the presence of the respective biocatalyst.

On the basis of these observations, we focused on the identification of selective donor substrates and discovered that an appropriate screening lead us to a broad variety of selectively reacting benzaldehyde derivatives. This screening was carried out by reacting 2-chlorobenzaldehyde with putative donors in the presence of BFD

\footnotetext{
* To whom correspondence should be addressed. E-mail: mi.mueller@fzjuelich.de.

${ }^{\dagger}$ Forschungszentrum Jülich.

¥ Heinrich-Heine Universität, Düsseldorf.

$\S$ Present addresses: A. S. Demir, Department of Chemistry, Middle East

Technical University, Ankara, Turkey. Martina Pohl, MPB Cologne GmbH,

Cologne, Germany.
}

Table 1. Combined Enzyme-Substrate Screening

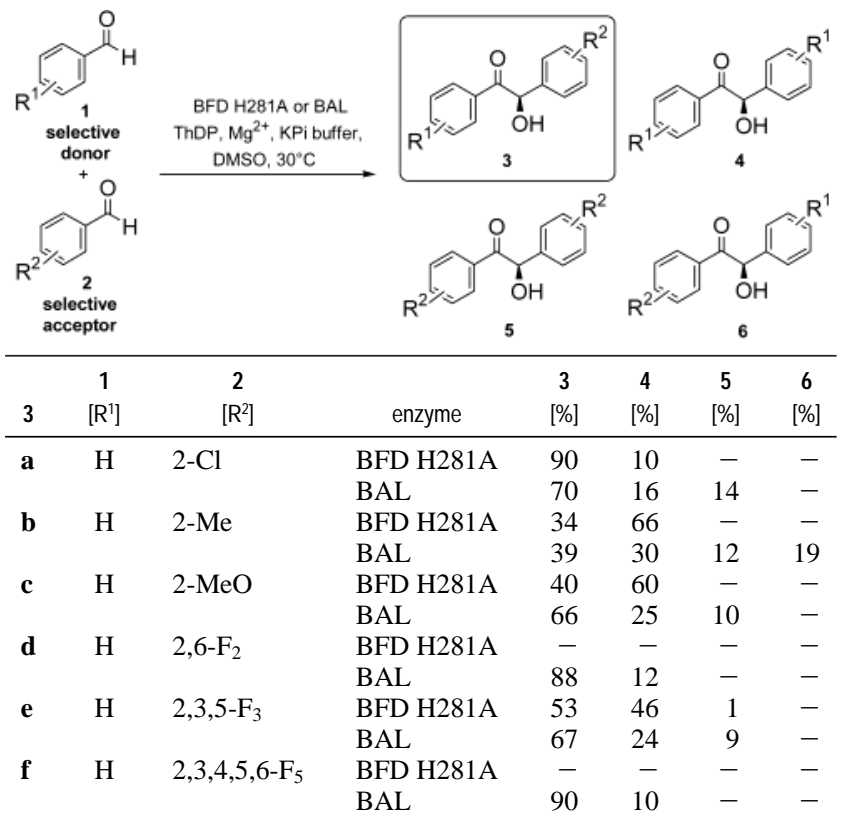

Table 2. Mixed Benzoins Synthesized Chemoselectively and Asymmetrically on a Preparative Scale ${ }^{a}$

\begin{tabular}{|c|c|c|c|c|c|c|}
\hline 3 & $\begin{array}{c}\text { donor } 1 \\
{\left[\mathrm{R}^{1}\right]}\end{array}$ & $\begin{array}{c}\text { acceptor } 2 a \\
{\left[R^{2}\right]}\end{array}$ & enzyme & $\begin{array}{c}\text { conversion } \\
{[\%]}\end{array}$ & $\begin{array}{c}\text { selectivity }^{b} \\
{[\%]}\end{array}$ & $\begin{array}{l}\mathrm{ee}^{\mathrm{c}} \\
{[\%]}\end{array}$ \\
\hline g & $3-\mathrm{CN}$ & $2-\mathrm{Cl}$ & BFD H281A & $>99$ & $>99$ & $90^{d}$ \\
\hline h & $4-\mathrm{Br}$ & $2-\mathrm{Cl}$ & BFD H281A & 90 & 95 & 95 \\
\hline i & $4-\mathrm{CF}_{3}$ & $2-\mathrm{Cl}$ & BFD H281A & 75 & $>99$ & 93 \\
\hline $\mathbf{j}$ & $3,4-\mathrm{CH}_{2} \mathrm{O}_{2}$ & $2-\mathrm{Cl}$ & BAL & 98 & 83 & $>99$ \\
\hline $\mathbf{k}$ & $3,4,5-\left(\mathrm{CH}_{3} \mathrm{O}\right)_{3}$ & $2-\mathrm{Cl}$ & BAL & 82 & 97 & $>99$ \\
\hline 1 & $3,5-\left(\mathrm{CH}_{3} \mathrm{O}\right)_{2}$ & $2-\mathrm{Cl}$ & BAL & $>99$ & 95 & $>99$ \\
\hline
\end{tabular}

${ }^{a}$ Experimental procedure: BFD H281A or BAL, ThDP, $\mathrm{Mg}^{2+}, \mathrm{KPi}$ buffer, DMSO, $30{ }^{\circ} \mathrm{C}, 24-48 \mathrm{~h} .{ }^{b}$ The selectivity is defined as the percent ratio of product in relation to the sum of all benzoins obtained. ${ }^{c}$ Determined by HPLC analysis. ${ }^{d}$ Compound $\mathbf{3 g}$ exhibits a strong racemization tendency.

H281A and BAL, respectively. Table 2 presents those examples of selectively obtained mixed benzoins that are likewise synthesized on a preparative scale $(0.2-1.5 \mathrm{~g})$ also with good-to-excellent conversion and chemoselectivity. Obviously, reactions catalyzed by these enzymes obey a donor-acceptor selectivity. Notably, the selectivity exhibited by the enzymes is different to the extent that BAL has a much broader substrate range concerning aromatic aldehydes with sterically demanding substituents, while BFD H281A shows a higher selectivity with aromatic aldehydes with 
Table 3. Preliminary Results of the Permutative Donor-Acceptor Screening Using BAL as Catalyst ${ }^{a}$

\begin{tabular}{|c|c|c|c|c|}
\hline 3 & donor $1\left[R^{1}\right]$ & acceptor $\mathbf{2}\left[\mathrm{R}^{2}\right]$ & conversion [\%] & selectivityb $[\%]$ \\
\hline $\mathbf{m}$ & $3-\mathrm{CN}$ & $2,6-F_{2}$ & $>99$ & 71 \\
\hline $\mathbf{n}$ & $4-\mathrm{Br}$ & $2,6-F_{2}$ & 98 & 66 \\
\hline $\mathbf{o}$ & $4-\mathrm{CF}_{3}$ & $2,6-F_{2}$ & $>99$ & 78 \\
\hline $\mathbf{p}$ & $3,4-\mathrm{CH}_{2} \mathrm{O}_{2}$ & $2,6-F_{2}$ & 97 & 72 \\
\hline $\mathbf{q}$ & $3,4,5-\left(\mathrm{CH}_{3} \mathrm{O}\right)_{3}$ & $2,6-F_{2}$ & 93 & 84 \\
\hline $\mathbf{r}$ & $3,5-\left(\mathrm{CH}_{3} \mathrm{O}\right)_{2}$ & $2,6-\mathrm{F}_{2}$ & $>99$ & 96 \\
\hline $\mathbf{s}$ & $3-\mathrm{CN}$ & $2,3,5-F_{3}$ & 89 & 66 \\
\hline $\mathbf{t}$ & $4-\mathrm{Br}$ & $2,3,5-F_{3}$ & $>99$ & 90 \\
\hline $\mathbf{u}$ & $4-\mathrm{CF}_{3}$ & $2,3,5-F_{3}$ & 94 & 78 \\
\hline $\mathbf{v}$ & $3,4-\mathrm{CH}_{2} \mathrm{O}_{2}$ & $2,3,5-\mathrm{F}_{3}$ & 40 & 94 \\
\hline $\mathbf{w}$ & $3,4,5-\left(\mathrm{CH}_{3} \mathrm{O}\right)_{3}$ & $2,3,5-\mathrm{F}_{3}$ & $>99$ & 83 \\
\hline $\mathbf{x}$ & $3,5-\left(\mathrm{CH}_{3} \mathrm{O}\right)_{2}$ & $2,3,5-F_{3}$ & 98 & 92 \\
\hline $\mathbf{y}$ & $3-\mathrm{CN}$ & $2,3,4,5,6-\mathrm{F}_{5}$ & $n c^{c}$ & - \\
\hline $\mathbf{z}$ & $4-\mathrm{Br}$ & $2,3,4,5,6-\mathrm{F}_{5}$ & $>99$ & 97 \\
\hline $\boldsymbol{\Gamma}$ & $4-\mathrm{CF}_{3}$ & $2,3,4,5,6-\mathrm{F}_{5}$ & 76 & 96 \\
\hline II & $3,4-\mathrm{CH}_{2} \mathrm{O}_{2}$ & $2,3,4,5,6-\mathrm{F}_{5}$ & $>99$ & $>99$ \\
\hline$\Sigma$ & $3,4,5-\left(\mathrm{CH}_{3} \mathrm{O}\right)_{3}$ & $2,3,4,5,6-\mathrm{F}_{5}$ & $>99$ & 92 \\
\hline $\boldsymbol{\Omega}$ & $3,5-\left(\mathrm{CH}_{3} \mathrm{O}\right)_{2}$ & $2,3,4,5,6-\mathrm{F}_{5}$ & $>99$ & $>99$ \\
\hline
\end{tabular}

${ }^{a}$ The selectivity was determined by gaschromatography. ${ }^{b}$ The selectivity is defined as the percent ratio of product in relation to the sum of all benzoins obtained. ${ }^{c}$ nc $=$ no conversion.

small substituents. Thus, the complementary substrate ranges of different enzymes enable the synthesis of a large diversity of mixed benzoins.

Evidence that the aldehydes used do not serve as selective acceptors only in the presence of one special donor, and vice versa, could be provided by an additional test series combining identified selective donors with selective acceptors in the presence of BAL (Table 3). In most of these attempts the mixed benzoin $\mathbf{3}$ was obtained with high-to-excellent selectivity.

To obtain access to the $(S)$-enantiomer of the mixed benzoins, we employed the kinetic racemic resolution via $\mathrm{C}-\mathrm{C}$ bond cleavage established for the BAL-catalyzed $(S)$-benzoin formation (Scheme 1). ${ }^{1 \text { a }}$ In doing so the enantiopure mixed $(S)$-benzoin $(\boldsymbol{S})$-3h was obtained with more than $49 \%$ conversion (ee $>99 \%$ ). Thus, both enantiomers of the mixed benzoins are accessible through this enzyme-catalyzed reaction.

Scheme 1. Generation of the Mixed (S)-Benzoin (S)-3h by Kinetic Racemic Resolution

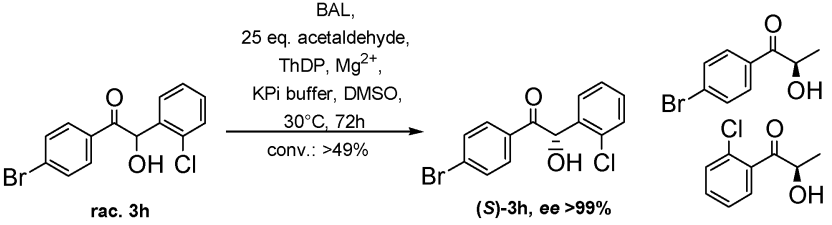

In summary, we have shown that mixed benzoins can be synthesized enantioselectively through an enzymatic cross-benzoin condensation by ThDP-dependent enzymes taking advantage of the aldehydes donor-acceptor behavior. This one-step synthesis starting from cheap and commercially available aldehydes represents an outstanding improvement in comparison to the costly and tedious synthesis based on the conversion of chiral cyanohydrines with phenyl-Grignard derivatives. ${ }^{4 a-c, 9}$ Essential for the realization of this concept was a successful implementation of both enzymatic and chemical mechanistic concerns. Moreover, we are convinced that the concept presented here should be transferable to reactions that proceed in a comparable manner, for example Tishchenko reactions ${ }^{10,11}$ or pinacol couplings. ${ }^{11,12}$ In this case, our work, stimulated by classic organic chemistry and carried out in the field of enzymatic synthesis, would lead us to an advanced insight into general chemical concerns.

Acknowledgment. The skillful technical assistance of Lydia Walter, Alia Akaouch, Sabine Schüller, and Ralf Feldmann is gratefully acknowledged. This work was supported by the Deutsche Forschungsgemeinschaft in the scope of SFB 380. A.S.D. thanks the DAAD and the Alexander von Humboldt Foundation for a fellowship.

Supporting Information Available: Experimental data for the compounds $\mathbf{3 a}, \mathbf{3 h}, \mathbf{3} \mathbf{j}$, and $\mathbf{3} \mathbf{\Pi}(\mathrm{PDF})$. This material is available free of charge via the Internet at http://pubs.acs.org.

\section{References}

(1) (a) Demir, A. S.; Pohl, M.; Janzen, E.; Müller, M. J. Chem. Soc., Perkin Trans. 1 2001, 633-635. (b) Demir, A. S.; Sesenoglu, Ö.; Eren, E.; Hosrik, B.; Pohl, M.; Janzen, E.; Kolter, D.; Feldmann, R.; Dünkelmann, P.; Müller, M. Adv. Synth. Catal. 2002, 344, 96-103.

(2) (a) Iding, H.; Dünnwald, T.; Greiner, L.; Liese, A.; Müller, M.; Siegert, P.; Grötzinger, J.; Demir, A. S.; Pohl, M. Chem. Eur. J. 2000, 6, 14831495. (b) Demir, A. S.; Dünnwald, T.; Iding, H.; Pohl, M.; Müller, M. Tetrahedron: Asymmetry 1999, 10, 4769-4774.

(3) Cf. Enders, D.; Breuer, K. In Comprehensive Asymmetric Catalysis; Jacobson, E. N., Pfaltz, A., Yamamoto, H., Eds.; Springer: Berlin, 1999 Vol. 2, pp 1093-1102.

(4) (a) Pirrung, M. C.; Fallon, L.; Lever, D. C.; Shuey, S. W. J. Org. Chem. 1996, 61, 2129-2136. (b) Pettit, G. R.; Lippert, J. W.; Herald, D. L. J. Org. Chem. 2000, 65, 7438-7444. (c) Ager, D. J.; Prakash, I.; Schaad D. R. Chem. Rev. 1996, 96, 835-875. (d) Jackson, W. R.; Jacobs, H. A.; Jayatilake, G. S.; Matthews, B. R.; Watson, K. G. Aust. J. Chem. 1990, 43, 2045-2062. (e) Shirai, R.; Takayama, H.; Nishikawa, A.; Koiso, Y ; Hashimoto, Y. Bioorg. Med. Chem. Lett. 1998, 8, 1997-2000.

(5) Buck, J. S.; Ide, W. S. In Organic Reactions; Adams, R., Bachmann, W. E., Blatt, H. A., Fieser, L. F., Johnson, J. R., Snyder, H. R., Eds.; Wiley: New York, 1949; Vol. 4, pp 269-304 and references therein.

(6) (a) Semerano, G. Gazz. Chim. Ital. 1941, 71, 447-461. (b) Merz, K. W ; Plauth, D. Chem. Ber. 1957, 90, 1747-1757. (c) We assume that at least in some cases the selective formation of one mixed benzoin might result from an isomerization, leading to the thermodynamically more stable product. In our case the observed enantioselectivity clearly proves the selective formation of the respective mixed benzoins. Cf (d) Corrie, J. E. T. Tetrahedron 1998, 54, 5407-5416. (e) Rozwadowska, M. D. Tetrahedron 1985, 41, 3135-3140.

(7) Polovnikova, L. S.; McLeish, M. J.; Sergienko, E. A.; Burgner, J. T.; Anderson, N. L.; Jordan, F.; Kenyon, G. L.; Hasson, M. S. Submitted for publication. We thank Dr. McLeish for kindly providing us with the BFD H281A gene.

(8) Since symmetric benzoins generated through wild-type BAL- and wildtype BFD-catalyzed reactions are of $R$-configuration, we assumed that the mixed benzoins 3 possess $R$-configuration, too. ${ }^{1,2}$ To scrutinize the absolute configuration of the mixed benzoins, $(R)-2$ '-chlorobenzoin $3 \mathbf{a}$ was prepared nonenzymatically starting from $(R)$-(2-chlorophenyl)-2trimethylsilyloxy-acetonitrile ${ }^{9}$ by means of a Grignard reaction with phenylmagnesium bromide.

(9) (a) Hayashi, M.; Matsuda, T.; Oguni, N. J. Chem. Soc., Chem. Commun. 1990, 1364-1365. (b) McKenzie, A.; Kelman, A. L. J. Chem. Soc. 1934 $412-418$

(10) (a) Tishchenko, W. Chem. Zentralbl. 1906, 77, 1309-1311. (b) Lin, I.; Day, A. R. J. Am. Chem. Soc. 1952, 74, 5133-5135.

(11) The transfer of our result to these types of reaction is plausible, as both reactions proceed in two steps, of which the first is the generation of an activated species by conversion of one substrate with a catalyst and since racemic cross-couplings have already been described for both reactions.

(12) (a) Robertson, G. M. In Comprehensive Organic Synthesis; Trost, B. M., Flemming, I., Pattenden, G., Eds.; Pergamon: Oxford, 1991; Vol. 3, pp 563-611. (b) Clerici, A.; Porta, O. J. Org. Chem. 1983, 48, 1690-1694. (c) Freudenberger, J. H.; Konradi, A. W.; Pederson, S. F. J. Am. Chem. Soc. 1989, 111, 8014-8016.

JA0271476 